\title{
Myelodysplastic Syndrome with Excess Blasts-2
}

National Cancer Institute

\section{Source}

National Cancer Institute. Myelodysplastic Syndrome with Excess Blasts-2. NCI

Thesaurus. Code C7168.

A myelodysplastic syndrome defined by $10-19 \%$ blasts in the bone marrow or 5-19\%

blasts in the blood. Approximately $33 \%$ of cases progress to acute leukemia. The prognosis is usually poor. 